\title{
The prediction of the economic effect of the energy-saving system implementation: corporate and regional aspects
}

\author{
T.A. Shindina ${ }^{1, *}$, and L.B. Kotova ${ }^{1}$ \\ ${ }^{1}$ South Ural state University, 454080 Chelyabinsk, Russia
}

\begin{abstract}
The solution of the energy-saving problem is connected with two main aspects: technical progress allowing the use of modern equipment and technologies with great efficiency; the development of an economic system which allows achieving development objectives and minimization of resource costs. In our article we are going to talk about the possibilities of formation and results evaluation when implementing energy-saving measures and we are going to present the results of the research on the interdependence of managerial impact and economic results. In this article we study an assessment method of activities at the enterprise according to the results of energy-saving measures, and we are going to present the results of the study of economic factors of their development, we are going to suggest a method for assessing the prognosis based on entropy methods. The development of a group of enterprises that produce rational results as the results of energy-saving measures of some companies taking into account synergy will allow us comment on the overall economic efficiency of the introduction of the energy-saving system in Russia as an element of social development.
\end{abstract}

\section{Introduction}

The energy sector of the economy of a country is complex, involving receiving, transferring, transformation and use of various types of energy and energy resources. It is where technological, economic and social components of social development meet and it is the control factor in ecological and economic spheres. The state of the complex and individual enterprises reflects, on the one hand, the environment state; on the other hand it reflects the level of economic development and quality of human reasoning (Fig. 1).

Fig. 1 shows the interconnection of the basic economic categories of the energy sector of the economy of a country taking into account interconnection and diffusion of concepts. Let us study them.

Nowadays useful application of energy primarily is associated with energy-saving. Energy-saving should be understood as a complex of measures dealing with implementing legal, organizational, scientific, production, technical and economic measures aimed at efficient (rational) use (and economical consumption) of fuel and energy resources (FER) with the beneficial effect of their use and for involvement of renewable energy sources in economic circulation.

In fact, energy-saving is the decline in energy consumption, which is possible on the basis of:

- development of the technology of forced reductions in consumption on the basis of technical means, for example, of lower power technology or forced break switches in resources use , etc.
- development of technologies for replenishing consumed energy based on renewable sources use;

- development of society, understanding the importance of lean behavior and creation of a culture of thrift, namely, self-restraint when one deals with energy use and finding ways of replacing energy needs.

In the review of potential areas of energy saving, as well as of policies and programs designed to achieve energy saving, an integrated approach to energy efficiency is very important. The efficiency measured at the macro level (the energy intensity of the economy of a country) is a key indicator characterizing the sustainability of energy sector development and the state in general. In fact, under energy efficiency one can understand the ratio of the results of the use of energy and the cost of their replenishment, which is possible on the basis of:

- management of national income associated with the development of society and global economies, aimed at cost savings in energy consumption;

- reserves management of natural resources, reasonable spending of various kinds of resources, the use of a system of optimization and the principles of careful attitude to nature aimed at reducing costs for energy resources;

- development of engineering and technology with the maximum possible coefficient of efficiency aimed at reducing costs, consumption and energy transfer. 


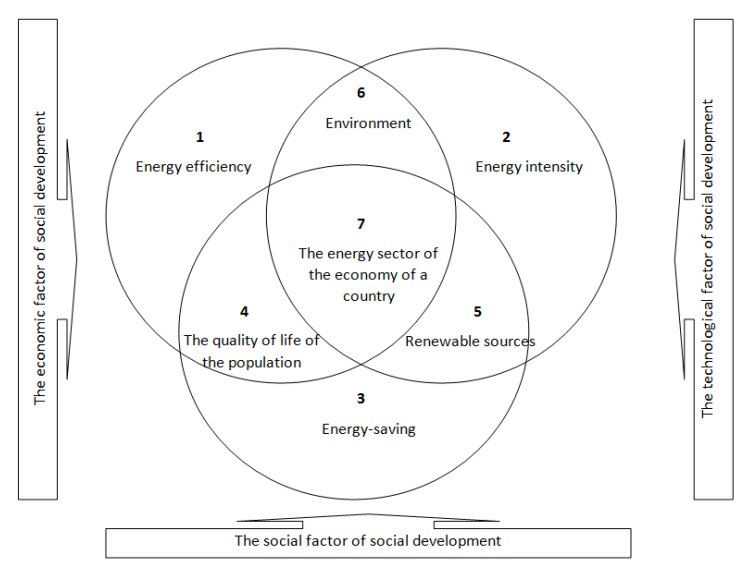

Fig. 1. The interconnection of the basic categories of the energy resources management.

The matters of cost reduction on energy connected with capacitive characteristics, which should be studied in the context of the concept of "energy intensity". Numerical expression of the intensity of the system is the indicator, which is the ratio of energy consumed by the system to the value characterizing the result of the operation of the system. In fact, under energy intensity one can understand power characteristics, reflecting the rate of speed change in continuous processes of consumption and accumulation of energy. The energy intensity shows certain resource endowment, which is possible on the basis of:

- increase in production volumes and reproduction in the dynamics;

- balance in the use of fuel substitutes (oil, gas, etc.);

- increase in the speed of resource replenishment at controlled consumption

In modern conditions of management energy-saving becomes a state priority, as it allows with the help of relatively simple measures of state regulation significantly reducing the load on budgets of all levels, restraining the growth of energy tariffs, increasing competitiveness of economy and increasing the supply in the labour market.

\section{Objectives, methodology and stages of the research}

The economic target of energy-saving is to minimize equipment costs and engineering services at regional enterprises that entail the effects of regional significance based on the principle of synergy.

The study of the economic results and the short term forecast is the research question which is relevant from the standpoint of ensuring social development of regions. There are two stages when conducting the study:

1. The forecast of economic efficiency of activities concerning energy saving at the enterprise.

2. The forecast of the economic effect in the region as the total of activities of enterprises and organizations that implement energy saving.

We are going to use a correlation and regression analysis, evaluation of plans reliability based on entropy and negentropy, analysis and synthesis of information as a methodological apparatus in order make predictions.

The main role in increasing the efficiency of energy use belongs to modern energy-saving technologies. Enterprises usually implement technologies that provide a significant energy-saving effect. These technologies associated with the energy use (motors with variable speed, heat exchangers, compressed air, lighting, steam, cooling, drying); more efficient energy production, including a modern boiler plants, cogeneration (heat and power), trigeneration (heat, cold, electricity); the replacement of the old industrial equipment with new, more efficient one; alternative sources of energy. In table 1 the main types of energy-saving technologies that are currently used are presented.

The whole complex of energy saving measures presented in the table has an engineering basis, but the essential roots of efficiency are economic in nature. Thus, the main research question which interests us from the point of view of energy saving is the direct economic impact on the enterprise and an indirect effect of regional importance.

\section{Discussion on the research outcomes}

In the article we study the impact of the above mentioned activities on enterprise costs.

In table 2 and 3 there are the data on direct costs of production of thermal energy and technological heat supply process from 2011 till 2015, and the data on generated energy. As we can see there are quite rhythmic fluctuations of costs from one period to another. The greatest increase in costs occurs in 2013, and further there is a gradual decline that is associated with the implementation of energy saving measures.

The most "vivid" picture is represented by two main indicators: natural gas and equipment repair (Fig.2). The economic indicator which reflects energy saving will be presented as the ratio of direct costs per 1 unit of produced energy, in fact it shows the dynamics of change of costs in ratio to the previous period.

However, the process of inflation and fluctuations in the financial system does not allow limiting in economic research on relative performance changes in costs. As we can see from the data in table 2 despite the fact that in 2014 there is no significant reduction in costs, at some point they increase. But it is not affected by the ultimate level of direct costs per 1 unit of produced energy, because in general there is an increase in development.

What will be with the enterprise along with the full implementation of the energy-saving program?

Predicted changes in the trend line on the indicators tab. 2 show the "conditional reduction" of costs for the next three years (2016-2018). Physical proof is the increase in the growth of energy production while reducing its cost.

The greatest effect from the introduction of the energy saving program can be seen in the reduction of costs for resources, repairs and maintenance of equipment. However, an important factor in the assessment is the uncertainty. For this purpose it is necessary to study the 
degree of uncertainty and disorder of costs by items of expenditure in relation to the benchmark presented earlier.

This analysis will allow us to assess the regularity of expenditure for the whole period of implementation of the energy-saving program, and it will provide an opportunity to highlight a priority for further detailed consideration of this problem.

Table 1. Styles Classification of energy-saving technologies.

\begin{tabular}{|c|c|c|c|c|c|c|}
\hline $\begin{array}{l}\text { Economic } \\
\text { sector }\end{array}$ & Construction & Industry & Agriculture & Transport & $\begin{array}{l}\text { Tertiary } \\
\text { sector }\end{array}$ & $\begin{array}{l}\text { Housing } \\
\text { and utility } \\
\text { sector }\end{array}$ \\
\hline \multicolumn{7}{|l|}{ Loss } \\
\hline $\begin{array}{l}\text { Decrease in } \\
\text { spending } \\
\text { amounts }\end{array}$ & $\begin{array}{l}\text { Automation of } \\
\text { processes of } \\
\text { consumption } \\
\text { (forced } \\
\text { disconnect, } \\
\text { modes change) }\end{array}$ & $\begin{array}{l}\text { Use of low } \\
\text { power } \\
\text { devices }\end{array}$ & $\begin{array}{l}\text { Technologies } \\
\text { of fossil } \\
\text { resources, } \\
\text { environmental } \\
\text { safety }\end{array}$ & $\begin{array}{l}\text { Reduction of } \\
\text { losses } \\
\text { technologies } \\
\text { (risks of theft, } \\
\text { loss of } \\
\text { transmission, } \\
\text { loss of } \\
\text { storage, etc.) }\end{array}$ & $\begin{array}{l}\text { Technologie } \\
\text { s of } \\
\text { resources } \\
\text { saving (heat, } \\
\text { light, etc.) }\end{array}$ & $\begin{array}{l}\text { Use of } \\
\text { metering } \\
\text { devices } \\
\text { (multirate } \\
\text { system) }\end{array}$ \\
\hline $\begin{array}{l}\text { Reducing of } \\
\text { needs }\end{array}$ & $\begin{array}{l}\text { Increase in } \\
\text { efficiency } \\
\text { coefficients of } \\
\text { devices }\end{array}$ & $\begin{array}{l}\text { Change of } \\
\text { tariff policy }\end{array}$ & $\begin{array}{l}\text { Biotechnology } \\
\text { replacing the } \\
\text { energy demand }\end{array}$ & $\begin{array}{l}\text { Tracking } \\
\text { device of } \\
\text { unauthorized } \\
\text { connections }\end{array}$ & $\begin{array}{l}\text { Renewable } \\
\text { energy } \\
\text { technologies }\end{array}$ & $\begin{array}{l}\text { Smart } \\
\text { lighting } \\
\text { technology }\end{array}$ \\
\hline $\begin{array}{l}\text { Reducing } \\
\text { energy costs }\end{array}$ & $\begin{array}{l}\text { Generating } \\
\text { capacity } \\
\text { technologies } \\
\text { (the use of } \\
\text { minerals, } \\
\text { materials } \\
\text { substitutes) }\end{array}$ & $\begin{array}{l}\text { Technologie } \\
\text { s of resource } \\
\text { saving } \\
\text { (water } \\
\text { saving, fuel, } \\
\text { gas, solar } \\
\text { energy) }\end{array}$ & $\begin{array}{l}\text { The principle of } \\
\text { non-waste } \\
\text { production }\end{array}$ & $\begin{array}{l}\text { The energy } \\
\text { efficiency } \\
\text { classes }\end{array}$ & $\begin{array}{l}\text { Technologie } \\
\text { s of } \\
\text { resources } \\
\text { procurement } \\
\text { (making or } \\
\text { buying) }\end{array}$ & $\begin{array}{l}\text { Technoligies } \\
\text { of energy } \\
\text { performance } \\
\text { certificates }\end{array}$ \\
\hline
\end{tabular}

Table 2. The cost of production of thermal energy and of technological heat supply process, thousands of rubles.

\begin{tabular}{|c|c|c|c|c|c|c|}
\hline № & Description of costs & 2011 year & 2012 year & 2013 year & 2014 year & 2015 year \\
\hline 1 & Salary & 2078.3 & 2259.1 & 2455.5 & 2780.0 & 2931,2 \\
\hline 2 & Fringe benefit expenses & 605.3 & 657.9 & 715.1 & 839.6 & 888,6 \\
\hline 3 & Natural gas & 23073.7 & 23885.8 & 25560.0 & 29865.5 & 30164,2 \\
\hline 4 & Maintenance of gas pipeline & 926.6 & 985.7 & 1048.6 & 213.8 & 352,3 \\
\hline 5 & Electrical energy & 3868.1 & 3792.3 & 3830.6 & 4088.6 & 4598,0 \\
\hline 6 & Water supply & 1620.1 & 1588.3 & 1604.3 & 1872.2 & 1970,5 \\
\hline 7 & Raw products and materials (reagent) & 96.7 & 95.7 & 97.7 & 265.2 & 173,7 \\
\hline 8 & Depreciation & 238.8 & 238.8 & 238.8 & 238.9 & 253,3 \\
\hline 9 & Repair and maintenance of equipment & 11535.6 & 12538.7 & 13629.0 & 8655.3 & 6299,5 \\
\hline \multicolumn{2}{|c|}{ Total direct costs } & 44043,2 & 46042.3 & 49179.6 & 48819.1 & 47631.3 \\
\hline
\end{tabular}

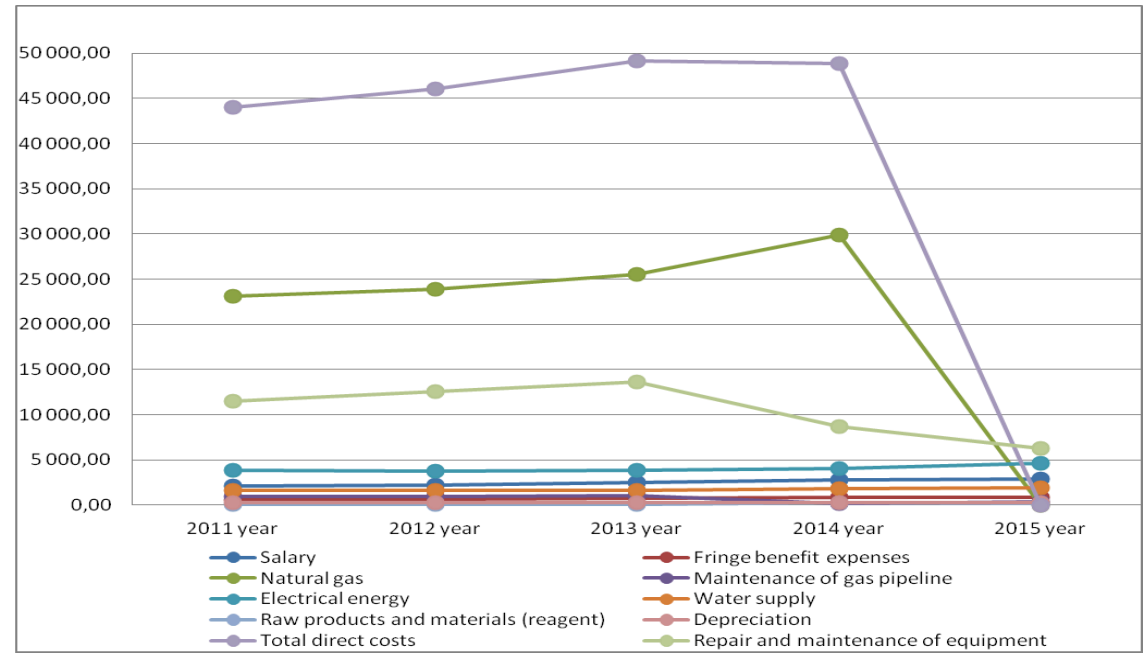

Fig. 2. Dynamics of changes in natural gas costs and repairs and maintenace of equipment, thousands of rubles. 
Table 3. Data on energy production of a boiler-house OJSC Electro machine

\begin{tabular}{|c|c|c|c|c|c|}
\hline \multirow{2}{*}{ Indicator } & \multicolumn{5}{|l|}{ Year } \\
\hline & 2011 & 2012 & 2013 & 2014 & 2015 \\
\hline Thermal energy, Gcal. & 39654.7 & 42154.2 & 45387.6 & 49241.8 & 45977.4 \\
\hline Technological heat supply process (steam), Gcal. & 10060.1 & 9465.3 & 9146.7 & 8979.0 & 8876.0 \\
\hline Energy production, Gcal. & 49714.8 & 51619.5 & 54534.3 & 58220.8 & 54853.4 \\
\hline Direct costs per $1 \mathrm{Gcal}$, rubles & 885.9 & 892.0 & 901.8 & 838.5 & 794.5 \\
\hline Growth rate, \% & & 0.7 & 1.1 & -7.0 & -5.2 \\
\hline
\end{tabular}

In order to account for the level of uncertainty we use the methodology of calculation of the entropy, which The results of calculation are presented graphically allows excluding the influence of random processes. Let us perform a calculation of all studied economic indicators.

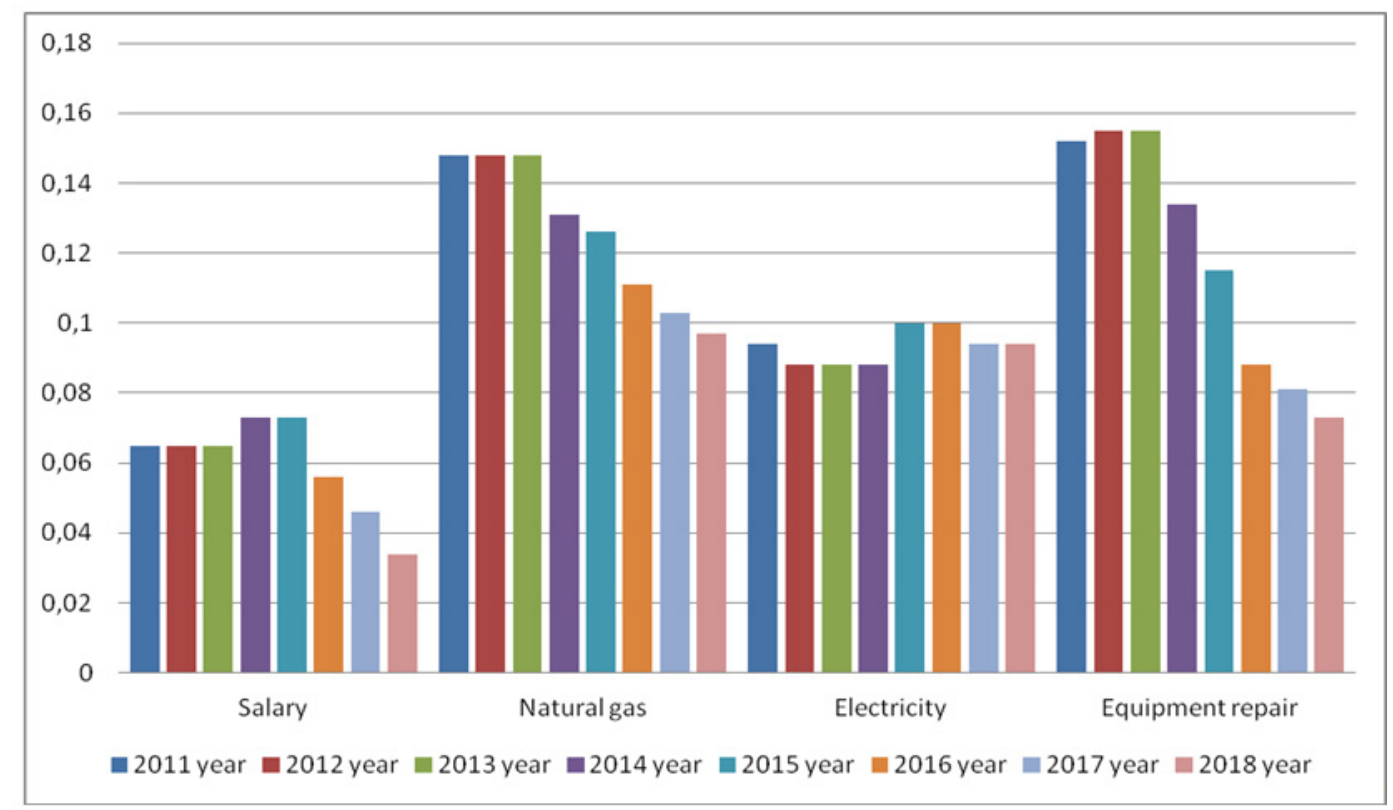

Fig. 3. Entropy of costs at the enterprise. 
The calculation will be done according to the formula:

$$
\mathrm{H}=-\sum_{\mathrm{i}=1}^{\mathrm{n}}\left(\mathrm{E}_{\mathrm{i}} \cdot \ln \left(E_{i}\right)\right)
$$

where $\mathrm{H}$ - the level of costs entropy, - the share of costs according to i-kind costs in the total direct costs.

As we can see on the chart the costs on natural gas and repairs and maintenance of equipment have the highest entropy, which shows that these costs are the most difficult to manage and they are more vulnerable to the effects of the produced energy. The payroll costs have the lowest entropy which shows that they are conditionally constant and are not dependent on volume of services.

As a rule managing the cost of natural gas purchasing can only be achieved by upgrading equipment, this is usually a one-time event, which is effective only in a certain period of time and only in natural units (e.g. in monetary terms, regardless of equipment upgrades, there will be an increase associated with the inflation of prices for the supply for this resource). Thus, it is the most "favorable material" for carrying out the research of influence of various factors concerning the reduction of costs and resource saving for repairs and maintenance of equipment.

Thus having considered the dynamics of changes in costs since the implementation of the energy-saving program until its end we can conclude that in spite of significant capital investments in the conditions of market instability, the company will have additional profit increase by reducing costs (at constant income).

\section{Conclusion}

Building an energy-efficient society in Russia includes forming the system of energy management with an optimally minimized cost, and ensuring the contribution of the energy factor in the country's economic development and in improving living standards.

Energy efficiency from the standpoint of enterprises complex gets a new content - regional and in a regional context it becomes a wide concept, accumulating in its semantic content minimization of specific energy consumption for successful social and economic functioning and development, as well as optimization of the contribution of the energy sector in the GDP, in the social improvement of society and economic well-being of the population and in protection of the environment.

To assess the development of Russian regions in the sphere of energy-saving and energy efficiency it is necessary to carry out a comprehensive analysis of the regional use of certain resources and the benefits from their use.

The spectrum of indicators of technological and economic nature allowed us to identify $10 \mathrm{key}$ indicators that influence the energy efficiency and the economy of the region. In order to form the most correct data, taking into account the result of the pair correlation of values obtained during the process of the analysis, we will rely on some key indicators, namely on an average annual temperature in the region, production and distribution of energy resources (management system of which we have considered above), as well as the emissions of pollutants into the air. The gross regional product will be presented as a dependent value (Fig. 4).

In the results of the correlation analysis we see that when evaluating the development of regions in the sphere of energy-saving and energy efficiency the least impact on the gross regional product value is made by an annual air temperature. The model taking into account the obtained weight coefficients can be represented by the formula:

$$
Y=5,85 \times 1+441,23 \times 2+18566,82 \times 3
$$

where $\mathrm{x} 1$ - average annual air temperature, $\mathrm{C}^{\circ}$; $\mathrm{x} 2-$ emissions of pollutants into the air, thousands of tons; $\mathrm{x} 3$-production and distribution of energy resources, millions of rubles.

The least change in the production of energy towards the increase or decrease will mostly be displayed in the development of the region as a whole. Emissions also improve the economic performance of the region, but they significantly reduce environmental performance. So, Russia has vast underutilized potential for energy saving, which is able to solve the problem of ensuring economic growth of the country that is comparable to the growth of production of all primary energy resources

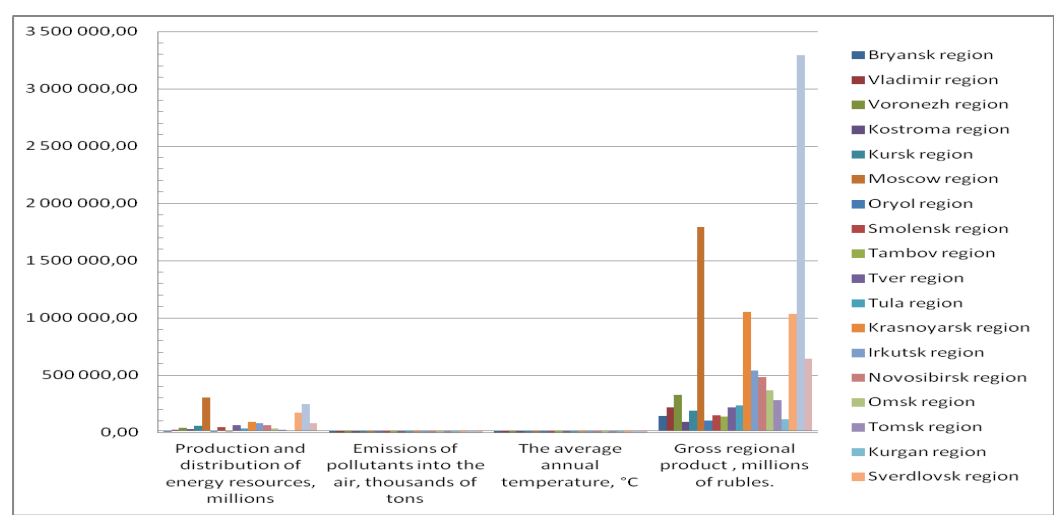

Fig. 4. Main indicators of activities in Russian regions. 
The work was supported by Act 211 Government of the Russian Federation, contract № 02.A03.21.0011.

\section{References}

1. D.F. Pires, C.H. Antunes, A.G. Martins, NSGA-II with local search for a multi-objective reactive power compensation problem (2012)

2. M. Doostizadeh, H. Ghasemi, A day-ahead electricity pricing model based on smart metering and demand-side management (2012)

3. L. Yang, C. Dong, C.L.J. Wan, C.T. Ng, Electricity time-of-use tariff with consumer behavior consideration (2013)

4. M.O. Abdullah, L.P. Yii, E. Junaidi, G. Tambi, M.A. Mustapha, Electricity cost saving comparison due to tariff change and ice thermal storage (ITS) usage based on a hybrid centrifugal-ITS system for buildings: A university district cooling perspective (2013)

5. I. Dincer, M.A. Rosen, Thermal energy storage: systems and applications (2010)

6. S.M. Hasnain, Review on sustainable thermal storage technologies, part I: heat storage materials and techniques (1998)

7. M. Ostry, P. Charvat, Materials for advanced heat storage in buildings (2013)

8. A.M. Khudhair, M.M. Farid, A review on energy conservation in building applications with thermal storage by latent heat using phase change materials (2004)

9. N. Zhu, Z. Ma, S. Wang, Dynamic characteristics and energy performance of buildings using phase change materials: A review (2009)

10. R. Baetens, B.P. Jelle, A. Gustavsen, Phase change materials for building applications: A state-of-theart review (2010)
11. F. Agyenim, N. Hewitt, P. Eames, M. Smyth, A review of materials, heat transfer and phase change problem formulation for latent heat thermal energy storage systems (LHTESS) (2010)

12. B. Zalba, J.M. Marin, L.F. Cabeza, H. Mehling, Review on thermal energy storage with phase change: materials, heat transfer analysis, and applications (2003)

13. M. Santamouris, G. Mihalakakou, C.A. Balaras, J.O. Lewis, M. Vallindras, A. Argiriou, Energy conservation $n$ greenhouses with buried pipes (1996)

14. C.-L. Su, M.-C. Lin, C.-H. Liao, A method for evaluating energy efficiency to justify power factor correction in ship power systems (2013)

15. X.-Y. Guo, Analysis of energy-saving real option investment based on normal clouds: Nonlinear system and control (2016)

16. W.-L. Cao, Y.-B. Zhang, H.-Y. Dong, Z.-Y. Zhou, J.-W. Zhang, Research and application on aseismic energy-saving structural system for rural buildings (2015)

17. M. Faccio, M. Gamberi, Energy saving in case of intermittent production by retrofitting service plant systems through inverter technology: A feasibility study (2014)

18. J.-G. Dong, Production organization strategy research and simulation based on energy-saving requirements of bulk cargo handling system

19. S. Siwamogsatham, P. Rattanawan, M. Kitjaroen, P. Sontung, P. Pongpailbool, K. Navanugraha, Smartly saving energy with a zero power consumption standby system

20. A. Yoshida, T. Sato, Y. Amano, K. Ito, Impact of electric battery degradation on cost- and energysaving characteristics of a residential photovoltaic system 